Article

\title{
The "Idle No More" Movement: Paradoxes of First Nations Inclusion in the Canadian Context
}

Terry Wotherspoon and John Hansen

Department of Sociology, University of Saskatchewan, 9 Campus Drive, Saskatoon, SK S7N 0E8, Canada; E-Mails: terry.wotherspoon@usask.ca (T.W.); john.hansen@usask.ca (J.H.); Tel.: +1 3069666925 (T.W.);

Fax: +13069666950 (T.W.)

\section{How to Cite this Article}

Wotherspoon, T., \& Hansen, J. (2013). The "Idle No More" Movement: Paradoxes of First Nations Inclusion in the Canadian Context. Social Inclusion, 1(1), 21-36.

\section{Acknowledgement}

This Article was published by Librello, Social Inclusion's former publisher.

\begin{abstract}
About the Journal
Social Inclusion is a peer-reviewed open access journal which provides academics and policy-makers with a forum to discuss and promote a more socially inclusive society. The journal encourages researchers to publish their results on topics concerning social and cultural cohesiveness, marginalized social groups, social stratification, minority-majority interaction, cultural diversity, national identity, and core-periphery relations, while making significant contributions to the understanding and enhancement of social inclusion worldwide.
\end{abstract}

www.cogitatiopress.com/socialinclusion

Editor-in-Chief

Professor Ulf R. Hedetoft, Faculty of Humanities, University of Copenhagen, Denmark

Managing Editor

Mr. António Vieira, Social Inclusion, Cogitatio Press, Portugal 


\title{
The "Idle No More" Movement: Paradoxes of First Nations Inclusion in the Canadian Context
}

Terry Wotherspoon* and John Hansen

Department of Sociology, University of Saskatchewan, 9 Campus Drive, Saskatoon, SK S7N 0E8, Canada; E-Mails: terry.wotherspoon@usask.ca (T.W.); john.hansen@usask.ca (J.H.); Tel.: +1 3069666925 (T.W.); Fax: +13069666950 (T.W.)

* Corresponding author

Submitted: 14 April 2013 | In revised form: 2 June 2013 | Accepted: 27 June 2013 | Published: 18 July 2013

\begin{abstract}
Idle No More, a recent protest movement initiated to draw attention to concerns by Indigenous people and allies about changes in Canada's environment and economic policies, has also raised awareness about social and economic conditions experienced by much of Canada's Indigenous population. While discourses and policies oriented to social inclusion are not as prominent in Canada as in Europe and several other contexts, these conditions and the strategies adopted by governments to address them are consistent with narrowly-framed inclusion policies. We provide an overview of what these conditions represent and how they have come to be framed in the context of the Idle No More movement. However, we extend our analysis to understand how the Idle No More movement and discourses of inclusion and exclusion alike have often been framed in ways that further limit solutions to the problems that they are oriented to resolve by stigmatizing and distancing Indigenous people, especially when they ignore or undermine distinct Indigenous rights and the foundations of formal Aboriginal status. We draw upon Indigenous concepts of justice and critical analyses of power relations in order to explore the contradictory locations and experiences associated with Indigenous inclusion in the Canadian context. We conclude by exploring the movement's contributions to broadened conceptions of inclusion that build upon alternative conceptions of socioeconomic participation and success.
\end{abstract}

Keywords: Indigenous people; social exclusion; social inclusion; social inequality

\section{Introduction}

News media in Canada and many other nations were replete with images in late 2012 and early 2013 of Indigenous people and their allies engaged in public rallies, flash mobs, marches, and occasional blockades that disrupted highway and rail traffic. Media exposure and public interest in the movement known as "Idle No More" (sometimes also referred to as "Canada's Native winter" in a nod to the "Arab spring" events) reached its 
peak in mid-January with events leading to high level talks between a delegation of First Nations leaders and the nation's Prime Minister and senior cabinet members. These events became the focus of international attention, drawing support and media coverage of environmental and Indigenous issues around the world while encouraging parallel rallies and protests in the United States, United Kingdom, Australia, and several other places. While the outcome was somewhat anticlimactic-entailing a commitment by government leaders to hold further talks to recognize and modernize the terms of historical treaties signed between First Nations and the crown (represented by Canada's Governor General, who met separately with members from the First Nations delegation)-the entire scenario played out as political theatre that alternatively captivated and puzzled much of its audience.

These events, and the debates and controversies surrounding them, drew attention to many profound issues associated with the status and conditions of Canada's Indigenous people. Adding to a long series of grievances and frustrations about inattention to longstanding problems, concerns were mounting that recently announced government policies that could further undermine conditions in many Indigenous communities were implemented without measures to secure adequate representation and dialogue with members of these communities. In the tense and uncertain build-up to the top level meetings, attention was focused especially on a high profile hunger strike led by Theresa Spence, a Chief from a northern Ontario First Nation community seeking action to address poor housing conditions, lack of running water, inadequate sewage, and other major and longstanding problems. While the media focus and surrounding public conversations about the movement heightened awareness of matters about which many Canadians had little knowledge, they also drew attention away from or distorted and misrepresented many of the core issues as participants with diverse interests came to position themselves through attempts to set the agenda or steer developments in ways that aligned with their own interests. The specific origins of the movement called Idle No More lay with concerns about broader contemporary fiscal and environmental issues relevant to Indigenous and non-Indigenous people alike, but the roots of the movement extended back several generations.

The Idle No More movement is significant for giving focus to the complex phenomenon of social inclusion and its implications for Indigenous people in the Canadian context. In particular, the challenges to define and achieve what it means for Indigenous people to maintain Indigenous rights (formally defined as Aboriginal rights in Canada) as well as their identities as Indigenous people while gaining meaningful participation in the political, social and economic life of the Canadian nation take place within a multidimensional and often highly volatile landscape. This paper explores the emergence of and public reactions to the Idle No More movement as both a response to processes of exclusion that have posed historic and contemporary limits to the opportunities available to much of the Indigenous population to become fully incorporated into Canadian society and as a struggle by diverse groups and interests to redefine and re-establish the bases on which such inclusion may be achieved.

It is crucial to locate processes of inclusion and exclusion, in these respects, within a framework that takes into account practices and legacies associated with colonization as well as the struggles to define and realize the distinct legal status and rights of Indigenous people. This means that, while attention needs to be given to problems associated with full inclusion of much of the Indigenous population with respect to conventional indicators such as education, housing or employment, several distinctive features of the Indigenous experience require a more nuanced understanding than can be offered through conventional discourses and objectives related to inclusion. Full and equitable inclusion within Canadian society cannot occur without fulfilling the nation to nation relationship between Indigenous people and Canadian governments outlined in historic treaties and subsequent legislation. In presenting our analysis, we draw from and contrast alternative discourses presented by Indigenous scholars, elders, and community representatives, government documents, and representations of Indigenous people and Idle No More in mass media and popular accounts. We adopt elements of Pierre Bourdieu's analytical framework, highlighting especially how the diverse places occupied by Indigenous people within Canadian society are influenced by symbolic violence and interactions influenced by unequal allocations of social, cultural and economic resources and power. Inclusion, understood in this way, requires awareness of the diverse and often contradictory realities and significance associated with the Indigenous experience within the Canadian context. We acknowledge the contemporary dimensions of Idle No More as a fluid, dynamic social movement which is, at the same time, deeply connected with the quest to validate and realize longstanding notions of Indigenous justice and law. We begin with a description of the roots and aims of the Idle No More Movement, understood from Indigenous perspectives, before proceeding to more detailed analysis of the various forms of social exclusion and struggles for inclusion in the Canadian context.

\section{Idle No More Roots and Aims}

The Idle No More movement is widely interpreted to be a contemporary movement. However, while the movement of that specific name is relatively recent, it is grounded in longstanding historical roots located within struggles to define and maintain Indigenous identity and foster effective Indigenous nationhood [1]. Its core vision is articulated in terms of objectives to work with 
allies to recognize First Nations sovereignty and nationhood and to employ an effective nation to nation relationship to foster social justice and protect the environment and lands in a respectful way [2].

It represents much more than the events and activities taking place under that specific label. Its most immediate roots lie with an initiative undertaken not by formal Indigenous leaders, but from unofficial leadersthree Indigenous women and one non-Indigenous woman in Saskatchewan-in the course of discussing how their concerns about recent measures hidden in massive budget legislation could be translated into action. Their stance against provisions contained within Bill C-45 (a massive piece of supplementary budget legislation introduced to Parliament by Canada's federal government in early 2012), communicated through social media and connections among communities, awakened the people and alerted them to commitments to fundamental responsibilities.

The movement is important because it is rooted in old Indigenous laws that speak of our duty to protect the water and land for the future generations. It marks the re-awakening of an Indigenous tradition and culture grounded in respect for the environment, fostering resistance to the kinds of exploitation of land and water conveyed through many of the terms of Bill C- 45 . The legislation is widely described and denounced by critics as an omnibus budget bill because it contained, in addition to fiscal provisions, an extensive series of changes to more than sixty federal acts and regulations, including the Indian Act and other legislative provisions that affect lands and resources in Indigenous territories. The Bill, as suggested in its title, The Jobs and Growth Act, 2012, prioritizes the government's commitment to economic initiatives in part by removing what it considers barriers to development [3]. Many of the provisions of the legislation, including those that affected Indigenous people and their lands and resources, appeared, without prior notice, embedded within a comprehensive 450 page document. The changes and the manner in which they were imposed by the federal government violated principles of consultation and relations with the environment fundamental to Indigenous rights and heritage. Although significant in its own right, the legislation reinforced a pattern in which the government has ignored more formal obligations, including those specified in Articles 19 and 32 of the United Nations Declaration on the Rights of Indigenous Peoples to consult and cooperate with indigenous people in order to secure their free and informed consent prior to implementing legislation or undertaking projects that may affect Indigenous people or their lands and resources $[4,5]$.

Idle No More has provided a focal point that enables contemporary Indigenous people and their allies to connect with an aspect of Indigenous culture that signifies a heritage designed to respect the environment and to prevent others from devastating the natural world. Within the context of Indigenous law,
Indigenous people are unique in that they are distinct nations (recognized formally as First Nations) within a Western State who have their own consciousness of law. The Indigenous way in this law entails a reciprocal relationship with the earth, water, plants and animals; the terms of Bill C-45, by contrast, are contrary to these relationships, marking only one of several instances in which the current Canadian government has ignored the reality of those laws.

Perhaps one of the important aspects of Idle No More is the support it has received from social justice advocates, environmentalists and other groups. Social media enabled the movement to gain rapid momentum and widespread exposure while mobilizing large gatherings for many of its events. It may not be surprising to find support from concerned environmentalist and social justice advocates, but it does also suggest deeper commitments that link social and ecological justice proponents with other dimensions of Indigenous struggles signified by Idle No More. Idle No More and its supporters believe that it is in humanity's best interests to protect the water and land, a struggle that entails related support on broader fronts including Indigenous nationalist struggles for autonomy, struggles to uphold Indigenous laws, and struggles for social, political and economic justice.

For Indigenous people, Bill C-45 represents a form of ongoing colonialism. Idle No More is both a specific movement and an awakening to re-engage in the ages-old resistance against colonialism and imperialism. Intrinsic to that awakening is the people's sense of Indigeneity and humanity that emerges from the recognition that Bill C-45 contains provisions that are likely to extend a colonial legacy in which Indigenous people have encountered numerous forms of oppression and inequalities. Based on most conventional indicators of social inclusion, much of the Indigenous population is among the most highly excluded and disadvantaged groups in Canada. Poverty rates among Indigenous people, overall, and especially among First Nations people living on reserves, are well above comparable levels for the population as a whole, as are incidences of other frequently-observed risk factors like unemployment, low education, poor health conditions, chronic illness and injury, suicide rates, and incarceration [6-8]. While the government has portrayed its resource-focused economic agenda as one that promises benefits from exploration, mining for oil and gas, and so-called development in Indigenous territories, there is extensive evidence to demonstrate that these benefits have not been experienced or shared equitably with Indigenous people and their communities [9].

The sections that follow will situate these issues in the context of historical factors and contemporary struggles in which social exclusion experienced by much of Canada's Indigenous population has fostered diverse understandings about and strategies to achieve meaningful inclusion. We examine the Idle No More movement within the framework of a relational under- 
standing of social inclusion, drawing from both western social theory and Indigenous perspectives in order to take into account relations of power, inequality and discourse as advanced through a relational understanding of social inclusion and exclusion.

\section{Socio-Legal Differentiation and Canada's Indigenous Population}

Before we continue the analysis, it is important to acknowledge several factors that have contributed to various forms of differentiation between Canada's Indigenous and non-Indigenous populations as well as within the Indigenous population. Indigenous people occupy various social positions, based in part on their distinct status (officially defined as Aboriginal people) in relation to non-Indigenous populations and with respect to specific categories of Aboriginal people within the nation's constitutional and legislative frameworks. Treaties signed with the British Crown prior to Confederation in 1867 and continuing to 1921, and subsequent comprehensive claims agreements (or "modern treaties") with the federal government, acknowledge the sovereignty of First Nations, as well as some Métis populations (mixed Indigenous and European heritage groups) and outline specific obligations of both parties to the treaties. The Indian Act and related legislation further defines "Indian" status and outlines rights and responsibilities related to those with Indian status, designating roles for the federal government in key areas, including education, social welfare, and health care which fall within areas of provincial jurisdiction for the general population. The Constitution Act (1982) and Charter of Rights and Freedoms further defines and reinforces rights for three groups of Aboriginal people, classified as First Nations, Métis, and Inuit. Many aspects of these legal definitions, including who is covered within them and what entitlements or obligations they carry, are subject to periodic contestation and revision. Frequent court challenges, political negotiation, and public protest have arisen for various reasons in efforts to clarify and resolve issues related to Aboriginal status (the terms and conditions of many treaties were violated or not honoured in practice, for instance, while negotiated treaties did not originally cover many Indigenous territories within Canada, leading to more recent land claims agreements and settlement protocols; there are also disparities and inconsistencies in the definitions, entitlements and responsibilities associated with distinct status groups). Resolution of these issues is further complicated by questions about who has the authority to represent, make decisions about, and provide programs and services for and on behalf of particular Indigenous groups. Gaps or inadequacies in key service areas, such as child and family welfare, education, public sanitation, and housing, have often been perpetuated for years because of federal and provincial disputes over which level of government is responsible for indi- viduals and families living in non-reserve or urban areas. More recently, Indigenous groups and other observers have identified inequalities in levels of funding and service provision as responsibilities have been devolved from federal government to First Nations jurisdiction. Compounding these issues, the Indian Act and other policies imposed European models of governance over First Nations living on reserves or affiliated with tribal agencies, creating structures of band and tribal government that ignore and sometimes conflict with longstanding patterns of governance and decision-making within Indigenous communities. These diverse categories and relationships have resulted in the emergence over time of several distinct organizations in which particular configurations of Indigenous populations are represented at band, regional, provincial and territorial, national, and sectoral levels, not all of which are recognized equally by one another or by federal government officials.

All of these factors mean that questions about what is meant by social inclusion, at what levels inclusion is to be achieved, and under whose terms or claims the meaning and nature of social inclusion comes to be understood, are likely to produce responses or outcomes that are highly uncertain, contested, and varied. The discourse of inclusion itself carries mixed significance for Indigenous people given their experiences with colonization and policies that have undermined their positions within Canadian society as well as their concerns that proposals to dismantle the Indian Act and related legislation could pose threats to the recognition of Indigenous knowledge, rights and status (see, e.g., $[8,10])$. Because of Canada's "long history of deeply entrenched racism," wrote the late Howard Adams, a prominent Metis scholar, "White supremacy, which had been propagated since the beginning of early European imperialism, became woven into Canadian institutions such as the church, the schools and the courts" [11]. In addition to divergent understandings concerning the implications of incorporation into dominant social institutions, there are many differing perspectives within Indigenous communities and among Indigenous scholars on the definition of and strategies to achieve Indigenous sovereignty within a nation to nation arrangement, especially in a global context in which the very meaning of nationhood is being challenged (see, e.g., [12-16]). Idle No More, in the search for common ground on many of these positions, reveals in the process the many paradoxes and contradictions also associated with these issues.

\section{Social Inclusion and the Production and Reproduction of Social Inequality}

A focus in both academic literature and policy analysis on questions related to social inclusion has drawn attention to the challenges posed by social inequality and the social, economic, and political consequences 
of social hierarchies within highly developed nations. Goals to achieve socially inclusive societies, along with related objectives to foster peaceful interaction, mutual recognition, and respectful dialogue, have a universal appeal ([17], p. 1). However, there are sometimes dangers that as policy discourses and instruments are realigned towards a focus on inclusion and exclusion rather than equality [18], priority is given to political containment and crisis aversion rather than to the true needs and aspirations of many segments of the population. In Canada, the predominant orientation to problems of social exclusion and inclusion within recent social policy has shifted from a liberal welfare state in the direction of what Banting ([19], pp. 419-423) calls "dis-embedded liberalism" representing a refocusing of policy emphasis away from measures to optimize income security for citizens and towards incentives driven by labour market participation and human capital development. These trends parallel a broader reframing of government activity in western welfare states from social expenditures to fiscal constraint and productive investment in productive enterprises while acknowledging the insecurity and disruption produced through globalization and market liberalization [18,20,21].

Federal, provincial and territorial governments in Canada have adopted numerous policy-related measures consistent with these liberal economic tendencies. Recent federal government policies have pushed this further by highlighting an economic agenda dominated by aggressive investment in profit-oriented activities, especially in oil and gas extraction, mining and other resource industries (see for example [22]), while restricting coverage of and eligibility for various forms of social assistance, restricting or realigning expenditures in education and other areas, and imposing demands for greater fiscal accountability in First Nations and other agencies to which government funds are transferred.

In order to offer an adequate understanding of how processes of social inclusion and exclusion are relevant to Indigenous populations in Canada, it is crucial to adopt a more nuanced conception of inclusion that takes into account Indigenous perspectives on knowledge and social engagement. This requires attention not simply to particular segments of the population that come to be posed as most vulnerable to marginalization and the consequences of such exclusion, but more importantly to how such exclusion and the inequalities in which it is embedded come to be produced and maintained within the social alignments and discourses that are the object of inclusive policies.

\subsection{Inclusion, Exclusion and Fields of Social Struggle}

Pierre Bourdieu's conceptualization of social life posed as fields of social struggle offers useful analytical tools that are compatible with a relational understanding of social inclusion $[23,24]$. It offers a way to address some of the conceptual and political issues not fully elaborated within some of the most widely adopted understandings of social inclusion in a manner that is compatible in significant ways with Indigenous experiences and perspectives on inclusion and inequality. Bourdieu draws attention to the observation that, while processes of social differentiation tend to foster hierarchical social structures that are relatively stable over time, these outcomes are neither strictly preordained nor based on the designs of any particular group. Bourdieu is especially concerned to explore how social actors located in specific social settings or locations position themselves to pursue the kinds of economic, social and cultural resources that are most highly valued within a given field, or domain of social life, while they are also engaged in defining the boundaries of the field and shaping the terms and conditions, or "rules of the game" by which the field is regulated.

Bourdieu's analysis, in common with the sociological exploration of social inclusion, was initially oriented to an understanding of the peculiar characteristics of modern French society, before being extended and adopted in a wide range of social contexts. However, whereas this analysis of social inclusion was rooted in Emile Durkheim's emphasis on social integration fostered by individual adaptations to the normative and performative obligations of the social order, Bourdieu's analysis of social fields focuses more fully on conflict and power relations, posing a more radical critique that suggests the way to new social possibilities (even if his work offers relatively limited guidance as to how things might become otherwise). The Durkheimian approach, allowing room for a soft critique of capitalism's worst consequences without calling for radical societal transformation [25], has tended to give way to an analytical looseness that has attracted an affinity especially among those promoting a "new" politics emphasizing a coalition of interests through the emergence of a middle or "third way" alternative to more radical left and right orientations. Social inclusion, in these policy discourses and orientations, is a matter of public concern largely because of its implications for problems of social cohesion and integration in a world in which global competition has potentially undermined longstanding loyalties to communities and nation-states. Inclusive strategies seek to reach, and reshape as productive citizens and workers, those individuals or groups deemed to be marginalized or disadvantaged within existing structural arrangements or whose economic and social status has become vulnerable in the course of dislocations produced by changing socioeconomic contexts $[25,26]$. While these discourses are often linked with genuine concerns to extend social justice and economic opportunity across the population, they also foster a temptation to pathologize risk and focus on exclusion as a consequence of the deficit inherent in those individuals or groups who are most vulnerable or at-risk. The terms and conditions under which exclusion and inclusion are determined are 
most likely to be established by those in positions of institutional or structural privilege rather than by those who are deemed to be excluded.

\subsection{The Symbolic Violence of State Policy}

State policies and related discourses help to frame national orientations to important spheres of activity, but they can also conceal and reinforce significant inequalities and interests. The dominant Canadian orientation to inclusion for Indigenous people, represented in the policies and pronouncements of the federal government as well as many provincial governments, is focused strongly on labour market integration. As a budget-related document, it is not surprising to see an economic focus in Bill C-45, but the implications of the legislation extend well beyond fiscal factors at the same time as other policy domains are defined predominantly in terms of economic interests. With respect to education, for example, Canada's Department of Aboriginal Affairs and Northern Development stresses that "The Government of Canada's overarching goal is to provide First Nation students with quality education that provides them with the opportunity to acquire the skills needed to enter the labour market and be full participants in a strong Canadian economy" [27]. This is a worthy goal but it cannot be achieved without a deeper understanding of, and action to address, the significant historical and contemporary factors that have made it difficult for many First Nations people to attain such skills. The language of full participation and equal opportunity, as posed in such policies, is not far removed from earlier policies of assimilation and cultural displacement, while failing at the same time to acknowledge the fundamental rights, traditions, and forms of knowledge that are essential to the achievement of the kinds of autonomy and identities essential to realize effective Indigenous nationhood.

This reduction of social complexity through a statemandated fiscal discourse represents what Bourdieu characterizes as symbolic violence with reference to the capacity within dominant groups or classes to impose meanings and assert them as neutral and legitimate while concealing the power relations through which they are asserted [23]. These processes, Lamont and Lareau ([28], p. 159) emphasize, contribute to social exclusion by monopolizing access to privileged positions and resources, representing "a power of legitimating the claim that specific cultural norms and practices are superior, and of institutionalizing these claims to regulate behavior and access to resources."

Social inclusion and exclusion are not marked by simple entry points into clearly defined or bounded statuses or positions; rather, they represent shifting reference points within and across particular social realms ([29], pp. 48-50). Bourdieu ([23], pp. 31-32) employs the notion of fields in sociological analysis in order to highlight how social inequalities may be reproduced over time within social structures that are nonetheless constituted by ongoing processes in a dynamic, fluid manner. These processes involve social participants who occupy distinct positions or social locations within various spheres of life, and who engage in both strategic actions and unconscious choices influenced by their positions in conjunction with particular configurations of social, cultural and economic resources upon which they are able to draw. Such resources, in turn, include not only material factors but also particular predispositions (forms of habitus) that include tacit knowledge as well as direct insights that influence their capacity for success in a given field. Each form of habitus is constituted by deeply engrained perceptions and understandings internalized though experience and socialization, especially in early life, but also cultivated through subsequent social positions or locations.

These differential positions and dispositions give rise to various, sometimes changing, alliances and oppositions as social participants within a particular field seek to define and pursue various types of objectives. In politics, law, education and other significant social fields, the meaning and nature of Indigenous identity and nationhood are themselves contested, at times within the Indigenous population as well as between Indigenous representatives and non-Indigenous groups. The diverse social positions and the varied experiences Indigenous people have had in relation to policies and practices associated with colonization, for instance (such as whether they or their family members attended residential schools, had treaty status, or resided on reserves), have contributed to the development of very different orientations to issues related to indigenous identity, rights and other crucial matters. Critics who pose frequently cited questions like "What is it that Indigenous people want?" or "Why can't they get their acts and lives together?" are missing the very straightforward reality that the Indigenous population, like the wider society of which it is part, is heterogeneous and changing, but it is also a product of a complex cultural and colonial heritage $[30,31]$.

Successful engagement within a given social field depends on having the appropriate predispositions, or habitus, required to negotiate the social relationships and understandings considered essential or legitimate within that field. While these may appear to be neutral or inevitable characteristics of given domains of social life, they are products not only of the positions people occupy within a specific field, but also of the capacity that people in those positions have to determine the boundaries, relationships and rules that define the field. The field of power is unique in that it overlaps with, and helps configure, all other fields, including the capacity to shape how different forms of capital may or may not be converted into one another. It is, Bourdieu ([23], p. 4) emphasizes, "the space of the relations of force between the different kinds of capital or, more precisely, between the agents who possess a sufficient amount of one of the different kinds of capital to be in 
a position to dominate the corresponding field, whose struggles intensify whenever the relative value of the different kinds of capital is questioned."

This conceptual framework is instructive for understanding the status and political aspirations of Indigenous populations in Canada. Indigenous people, widely portrayed in policy documents and social analysis as representing some of the most disadvantaged groups within Canada, have also long promoted visions of self-determination that are not confined to western or European-based notions of representation, integration and success. They encompass, through their heritage, contemporary status and aspirations, diverse predispositions, or forms of habitus through which they orient themselves to particular forms of capital, that combine deep cultural values that are aligned in disparate ways with dominant institutional practices and values, especially when understood in the context of Canada's dark colonial history.

These complex factors have helped to shape the Idle No More movement, which has provided a way to unite Indigenous people through a phenomenon that fosters opportunities for them to articulate their distinct status as Indigenous people in relation to demands associated with membership within the Canadian nation while solidifying their identity through connections with their Indigenous heritage. However, representative of diverse social positions and political aspirations represented among Indigenous populations, Idle No More has also been characterized by a variety of different, and sometimes conflicting, aims and orientations. Its proponents have articulated clearly its vision to serve as a socially and environmentally responsible grassroots movement dedicated to democratic practice and principles, but it has sometimes had difficulty establishing a clear public identity because so much of the media attention and external commentary has focused on actions of political leaders as well as more confrontational events, such as periodic blockages of transportation routes or industrial sites [32].

\section{Indigenous Justice and Idle No More}

In the most general sense, recognition of Indigenous laws and culture, which are vital components of the Idle No More movement, provide a means by which to demonstrate alternatives that may be posed to current official policy directions. The basic cultural orientations of the movement are: a vision to protect the land and water that leads to sustaining rather than exploiting the environment; values that promote peace and social harmony; and the attribution of a social justice dimension that includes rather than excludes the community.

Idle No More expresses Indigenous nationhood in its broadest sense, interpreted as a community of Indigenous people who share a common culture, values, history, and traditions including cultural teachings and the justice practices that permeate Indi- genous communities. The purpose of Indigenous law, as Yazzie and Zion emphasize, "is not a process to punish or penalize people, but to teach them how to live a better life. It is a healing process that either restores good relationships among people or, if they do not have good relations to begin with, fosters and nourishes a healthy environment" ([33], p. 160). Commitment to sustaining a healthy environment is basic to Indigenous laws. Such laws, also called teachings, are the cornerstone of Idle No More.

According to the Cree Elder Dennis Thorne, the creator gave to Indigenous people laws to live by that were based on selective values and teachings, such as reciprocity, sharing and respect. The Indigenous laws and culture are as expressed by Dennis (cited in [34], p. 166):

I have to look at the foundation of our laws. When the creator first put the Indigenous people on this earth no matter what nation or what country they were given laws to live by. According to the Cree and the First Nations in Canada they were given a way of life they were given instructions on how to live they were given responsibilities on how to look after the land, the animals, and the water. You may hear some elders say that they were stewards of the land. What they mean is they made an agreement with the animals a long time ago. In the time when they could communicate with the animals they spoke the same language and the animals said that they would give their lives to us to eat if we respected them and looked after them. To give something back, the first hunt the first kill, whether it was animals or fish, the four legged to give something back in order to respect the life that they gave.

Dennis refers here to the spiritual connection to the land: "they were given laws to live by", and also points out the responsibility Indigenous people have to "look after the land, the animals, and the water", also indirectly illustrating the importance of protecting the environment. Dennis maintains that:

Today is a big issue about environment. There wasn't from our thinking that the environment turned out the way it did. It was from another way of looking at life and other worldview that is not ours so today we all have to suffer. And if we take another look at our laws I think we can help them understand that our laws are not based on greed... Ours is based on good health, help, understanding and happiness. Our laws are for those four things only, for the survival of the people, for the survival of medicines, the survival of animals, the winged ones. So these laws are not only to protect the earth, but all humans all life (cited in [34], p. 167).

Subsequent notions pertaining to the environment reveal that Indigenous laws have invariably influenced Idle No More as the guiding principles behind the movement. 
John Martin, a prominent Elder from Northern Manitoba, observes that Indigenous people have a different law that is in harmony with nature:

There are two laws, the law of nature with the creator and the law of manmade. Anything that has to do with nature we know we have to be careful in how we conduct ourselves, how we treat people, anything like that in how we treat it...You see in life, in our way, which we are as a person, I am a Cree they say, but for me the word Cree doesn't mean anything to me. Being Inninew, I am a four directions person. That's what it means, Inninew it means four, I have my mind, my body, and also I have a spiritual being, I have feelings (cited in [34], p. 163).

This passage by Elder John Martin demonstrates the cultural responsibility that Indigenous people have to respect the laws of nature, that is, corresponding to the laws of the creator and to our commitment to conduct ourselves for the benefit of all existence. The way to this declaration is through our own identity and culture. The language of the Inninew (Cree people), in common with that of other Indigenous people, is crucial to understanding one's identity. The Cree word, Inninew (Cree people) for example, connotes a holistic understanding of identity. John explains that Inninew translates as 'a four directions person'-the mental, physical, spiritual and emotional human domains.

For John and Dennis, Indigenous laws and values are such that the environment is to be sustained out of respect for the future unborn, therefore speaking to a culture that espouses a deep connection to the land; the connection is manifest in responsibility to serve as "stewards of the land", a philosophy that has survived to the present day. This connection to the land is a core part of understanding the Idle No More movement, which is guided by traditional teachings in its more specific resistance to the omnibus Bill C-45 passed by the Conservative government. In short, the Indigenous world has not forgotten its cultural laws and values, despite the fact the Indigenous people have experienced several generations of imperialism.

While Idle No More was initiated through Cree understandings of law, respect for the environment and cultural values, its rapid expansion across communities throughout Canada and beyond speaks to these deeper responsibilities. According to the Chickasaw law scholar James Youngblood Henderson, Indigenous societies established a holistic law system that was grounded in the ecosystem. He writes:

Most Aboriginal orders do not impose order on relationships by establishing rules that govern general categories of acts and persons and then using these rules to decide particular disputes. Instead they determine that harmony; trust, sharing, and kindness are the shared ends of the circle and then make choices that contribute to these goals...Aboriginal laws are more about respect for every process in an ecosystem than about power over them. Aboriginal law is the law of speaking softly, walking humbly and acting compassionately ([35], p. 273).

The holistic understanding of Indigenous laws embraces the ecosystem and the premises of harmony, reciprocity and trust, which encourages the people to protect the environment. In the Indigenous laws, therefore, wholeness is present that designates respect for nature and forms the basis of Idle No More.

These non-western conceptions of justice and law are linked with struggles that are prompting new understandings about what it means to be Indigenous in a Canadian context. One of the strengths of the Idle No More movement has been its capacity to foster greater understandings of identity and cultural relationships while reinvigorating Indigenous knowledge systems that have been undermined and devalued through colonization and subsequent policies and institutional frameworks. Connection with this cultural heritage provides a crucial basis for the recognition of Indigenous social and cultural resources that represent, in a Bourdieuian sense, forms of capital that are essential both as foundations for Indigenous identity and as resources in the struggle to establish alternatives to dominant economic and political directions in which Indigenous people and their interests have been largely subordinated despite official renouncement of the colonial past.

\section{Colonialism Past and Present}

Although Eurocentric historians and sociological theories of development typically interpret colonization as bringing progress and benefit to backwards and inferior people, in reality colonization brought great harm to Indigenous families and communities. Elizabeth Comack notes that "European colonizers to take control over the lives of Aboriginal people involved a number of strategies, including the signing of treaties, the Indian Act, the residential school system, the North West Mounted Police played an instrumental role in carrying out this colonial project or civilizing mission" ([36], p. 73). Employing Bourdieu's concepts, the colonial project was oriented to modifying the prevalent forms of habitus or dispositions within the Indigenous population while repositioning Indigenous people relative to newcomers and authorities within social and economic structures. Processes that served to devalue and subordinate Indigenous knowledge and cultural resources coexisted with policies and practices that were exclusive in nature, producing significant inequalities or barriers to advancement with respect to education, employment and other significant fields of social, economic and political life.

From mainstream perspectives, the era of colonialism may have ended between the late nineteenth 
and mid-twentieth centuries, when former British colonies such as Canada, New Zealand and Australia were granted independence. Indigenous peoples, though, remained under colonial rule. Yazzie notes that, "the original inhabitants of those lands, Australian Aborigines, Maoris of New Zealand, and the First Nations of Canada, did not get their independence" ([37], p. 43). Although post-colonial discourse claims that colonialism is a thing of the past, Indigenous thinkers recognize that colonialism is being continuously reproduced in various forms. Indigenous people have experienced hundreds of years of imperialism and social exclusion, resulting in a legacy with respect to outcomes and social practices that have been perpetuated to the present day. Comack observes that "colonialism has produced the social and economic marginalization of Aboriginal people in contemporary Canadian society" ([36], p. 81). Canada's Truth and Reconciliation Commission, established by the federal government in 2008 in order to investigate the activities and impact of the residential school system that delivered education to many Indigenous children and youth in Canada for over a century beginning in 1883, portrays the system as a colonial "assault" on Indigenous children, families, culture, leadership, and selfgovernance that continues to shape people's total life experience in communities across the nation ([38], pp. 25-26). The commissioners emphasize that it is not sufficient to know how "the schools were central to the colonization of the Aboriginal peoples of Canada", but, more fundamentally, we need to recognize that "the colonial framework of which they were a central element has not been dismantled" ([39], pp. $2-3$ ). The passage and implementation of the terms of Bill C- 45 by the federal government in 2012 without consulting Indigenous nations represents further the processes of colonialism and social exclusion referred to by the commissioners. It is in this context that, from an Indigenous perspective, Prime Minister Stephen Harper's initial reluctance to meet with Chief Theresa Spence and acknowledge her demands represented further distancing between government and Indigenous positions reinforcing the exclusion of the latter. Such unilateral decisions to dismiss or exclude the Indigenous community while attending to other positions are taken as typical of colonial power relations that result in reproducing the marginalization of Indigenous people and communities.

In contrast to and in direct violation of Indigenous principles of law, the history of Western colonialism saw imperial states increase their power by imposing their laws on the Indigenous societies of continents outside Europe. A major manifestation of increasing State rule over Indigenous people in Canada was the criminal justice system. In her analysis of Canada's Indigenous justice system, Sutherland demonstrates that Western laws were used to subjugate and control Indigenous people:
Any resistance to these laws were made illegal and contributed to eroding indigenous political structures... it was illegal for First Nations people to go to court to sue the Government of Canada without previous permission from the government ...Some laws and policies were directed at the heart of First Nations' culture and spirituality. For example gatherings such as potlatches were outlawed while Christmas celebrations were encouraged...It was illegal to practice traditional healing...When attempts to disrupt economic, political, and spiritual infrastructures did not sufficiently assimilate 'Indians' children became the targets ([40], p. 6).

The passage demonstrates the role played by imperialistic Canadian laws to colonize Indigenous people who had no legal recourse to protect and maintain their culture. Since all power was placed in the colonizers' domain, Western state powers systematically overwhelmed Indigenous nations and denied them their most basic human rights. Such domination served not only to exclude Indigenous people from key spaces within the core fields of public life, but was also maintained by forms of symbolic violence that failed to acknowledge Indigenous knowledge and imposed new expectations about Indigenous identity, or habitus, within a Western framework.

\subsection{Shaping Indigenous Claims and Identities by Erasing Indigenous Memory and Nationhood}

Henderson shows how Canadian laws have been used to marginalize and exclude Indigenous people, observing that, "in Canadian thought, for example, Aboriginal nationhood, rights, and treaties are banished from mainstream culture and law and replaced by the theory of two founding nations: the English and the French" ([35], p. 65). Such social exclusion is typical of colonial practices that omit Indigenous contributions. He emphasizes, further, that colonizers aim to "obscure Aboriginal memory. To strip Indigenous people of their heritage and identity, the colonial education and legal systems induce collective amnesia that alienates Indigenous peoples from their elders, their linguistic consciousness, and their order of the world" ([35], p. 65). We explore the erosion of Indigenous memory and the symbolic violence these processes represent with reference to examples drawn from the fields of education and criminal justice, but these domains are embedded within a much broader set of dynamics. Nobles, for instance, observes with respect to state apologies for historical injustices that such actions seek to "alter the terms and meanings of national membership," thereby contributing to prospects for a more inclusive society [41]. These terms, nonetheless, are highly contested and linked to processes that, while reframing historical memory, can also reinforce or foster exclusion in other respects.

The Idle No More movement and the widespread 
support it has received is indication that Indigenous memory still exists. Whereas Bill C-45 illustrates how colonization continues in practice, if not in name, the response it has generated in the form of Idle No More suggests a move towards reclaiming the terrain on which postcolonialism may be established. Yazzie observes that:

Postcolonialism will not arrive for Indigenous peoples until they are able to make their own decisions. Colonialism remains when national legislatures and policy makers make decisions for Indigenous peoples, tell them what they can and cannot do, refuse to support them, or effectively shut them out of the process ([37], p. 43).

Similarly, Smith advises, "Many indigenous intellectuals actively resist participating in any discussion within the discourses of post-coloniality. This is because post-colonialism is viewed as the convenient invention of Western intellectuals which reinscribes their power to define the world" ([42], p. 14). In this context, Idle No More as a response to the Conservative government's Bill C-45 that represents, in the face of recurring broken promises by governments to engage in meaningful consultation with Indigenous people on matters that concern their land, communities and people, yet another unilateral decision that excludes Indigenous people and perspectives. Idle No More is the manifestation of resistance to colonialism.

\section{Social Inclusion and Indigenous People in Canada}

In contrast with Europe and many other contexts, the language of social inclusion has not been employed widely beyond adoption by a few government departments and non-government organizations that work with federal and provincial agencies in Canada. Regardless of the discourse employed, however, federal, provincial and territorial governments are engaging in an extensive range of action plans in response to serious problems confronting Indigenous populations across the nation. An ongoing series of inquiries, studies and official documents, both before and after the wide-sweeping Royal Commission on Aboriginal Peoples produced its five volume report in the mid1990s, has drawn attention to the pressing need for action on numerous fronts. Collectively, these reports reveal Indigenous populations have a high degree of being excluded with respect to virtually every dimension around which social inclusion and exclusion is considered significant. Demonstrated concerns and calls for action in Indigenous communities correspond, for instance, with each of the factors associated with exclusion identified by Atkinson and Marlier in a report for the United Nations relative to both core indicators (encompassing income and material deprivation, productive role, education status, health, and housing conditions) and social factors (including access to rights and realms such as social and political participation, civil rights, security and justice, well-being, information and communication, and mobility, leisure and culture) ([43], p. 40).

There are several dangers, nonetheless, in approaching these issues too narrowly in terms of deprivation, disadvantage and exclusion. A deficit orientation, while drawing attention to many areas in which urgent action is necessary in order to alleviate pressing material and social needs, is limited insofar as it fails to take into account alternative ways in which success, capacities and inclusion may be understood, ignoring, in the process, the forms of exclusion entrenched within the assumptions and processes by which indicators and outcomes associated with inclusion come to be defined and sustained.

The sometimes perplexing and confounding politics and activities associated with the Idle No More movement are an expression of these complex relationships. As the preceding discussion of colonialism emphasizes, the Indigenous experience in Canada has frequently encompassed social inequality, racialization and social exclusion. The phenomenon of over-representation by Indigenous people in the criminal justice system, which has for several decades been the focus of periodic inquiries and reports by governments and other agencies in Canada, offers striking evidence of that exclusion. Since the colonization of the Indigenous world most Indigenous peoples living in colonial societies have experienced some form of social exclusion or racism. In an analysis of the concept of social exclusion, sociologist Elizabeth Comack, draws a parallel between Indigenous 'social exclusion' and 'colonialism.' There is extensive evidence of how discourses of colonialism, racism and social exclusion have been exhibited by the police, courts and others in the process of interpreting Indigeneity in accordance with racial constructs. Comack writes that, "Race and racism not only pervade the everyday lives of Aboriginal people, but also inform the wider public discourses and institutional processes...including the processes of law enforcement" ([36], pp. 13-14).

\subsection{Overlapping Layers of Social Regulation and Exclusion}

Indigenous people have been stereotyped as criminal types, lazy and inferior to the mainstream, and these gross distortions of Indigeneity are reflected in the phenomena of racialized policing. Comack, for instance, interviewed 78 Indigenous participants who reside in Winnipeg's North End or inner city. What she found in the participants' collective narrative was the commonly held notion that Winnipeg police officers have routinely racialized, degraded and dehumanized Indigenous people. Comack observes, "Aboriginal men are regularly stopped by police, sometimes on a weekly basis, and asked to account for themselves" ([36], p. 
210). The same racial stereotyping is demonstrated when police assume that Indigenous males are drug dealers or gangsters while Indigenous women are seen as prostitutes ([36], p. 25). In fact, participants reported that the police have referred to them in terms of 'squaw', 'dirty Indian', or 'fuckin Indian'. These kinds of insults are a powerful means of degrading Indigenous people. However, reinforcing the limited social and cultural capital to combat such symbolic violence, Comack's participants were powerless to do much about because Indigenous people are viewed as not credible and their complaints on police misconduct are not taken seriously.

The racialization of Indigenous people has invariably led to social exclusion from society's core institutions, including employment, education, housing, policing, and many other sites. Imperialism and racialization in the criminal justice system has been an important factor contributing to over-representation of Indigenous people in the justice system: its tools were the police, courts and racialization. The Canadian Criminal Justice Association observes that Indigenous people, "especially in the north spend less time with their lawyers...are less likely to have legal representation in court proceedings...and they often plead guilty because they feel intimidated by court proceedings and want them over with" ([44], p. 38). These kinds of practices demonstrate that the criminal justice system treats Indigenous people as marginal and therefore helps to explain their over-representation in the prisons. A federal report released in 2012 reveals that Indigenous men and women are significantly over-represented in Canada's federal penitentiaries; according to Howard Sapers, Canada's ombudsman for incarcerated human beings, these proportions are expanding rapidly, especially in the Prairie Provinces where Indigenous people are most highly concentrated: "Of the growth, 52 per cent has come from the Prairies. It's the fastest-growing region in the country and aboriginal offenders account for most of the increase and account for 43 per cent of the offenders in that region" $[45,46]$.

It has been said of the prison system that it obstructs the potential for healing and therefore reproduces a cycle of crime. As Braithwaite advises:

Prisons are schools for crime; offenders learn new skills for the illegitimate labor market in prison and become more deeply enmeshed in criminal subcultures. Prison can be an embittering experience that leaves offenders more angry at the world than when they went in ([47], p. 1738).

For Braithwaite the prison experience develops crime skills and increases bitterness therefore it is not surprising that recidivism rates are high. To be more concrete, The Commission on First Nations and Métis Peoples and Justice Reform observes that "empirical evidence in the U.S., Canada, and Europe over the last 30 years shows longer sentences do not reduce recidivism" and "longer sentences may increase recidivism" ([48], pp. 9-41). The Commission goes on to state that "Canada is a world leader in incarcerating 118 per 100,000 general population" ([48, p. 9-41). In its tendency to remove people from community and social participation, especially in the absence of programs and initiatives to foster reintegration in the community upon release, it is clear that the criminal justice system does not advance social inclusion as a priority in its dealings with Indigenous offenders.

These patterns are consistent with what Michel Foucault recognized more generally as the failure of prisons in observing that "those leaving prison have more chance than before of going back to it; convicts are, in a very high proportion, former inmates" ([49], p. 265). Foucault maintains that the "prison cannot fail to produce delinquents by imposing violent constraints on its inmates; it is supposed to apply law, and to teach respect for it; but all its functioning operates in the form of an abuse of power" ([49], p. 266).

These phenomena represent more widely observed disconnections that Indigenous people often encounter between predispositions developed early in life, rooted in their family and cultural heritage, and those expected or expressed in relationships with dominant Canadian institutions. Even concepts related to social inclusion, rooted in Western epistemologies tend to diverge from discourses associated with Indigenous people and their experiences. Consequently, there are limits to the extent to which these concepts, and especially the methodologies employed to determine indices of social inclusion and exclusion, are able to encompass important dimensions of Indigenous people's realities. Responding to panel presentations at a conference on social inclusion in Canada, for instance, Inuit audience members observed particular actions or statuses in northern Indigenous social contexts take on different meanings than when interpreted from a southern, urban vantage point:

One pointed out that when Inuit drop out of high school, they often go out on the land and provide for their people in a valuable way, but this is not captured in the research. She added that Inuit are not highly represented in post-secondary education because going to a southern university is like going to a different country for Inuit-and because it is not their tradition for parents to provide for this education. The participants stressed that Inuit as well as other Aboriginal people must be a part of all policy, research and legislation [50].

This passage demonstrates that the formal high school education is irrelevant to some Inuit who drop out in high numbers in comparison to the mainstream. The Canadian middle class standards and ideals mean little to the practical life of the Inuit and other northern Indigenous learners. We would have to see that the basis of mainstream schools, which is to teach the language, values and culture of the colon- 
izer, at the same time treats the culture, language and ways of the Inuit as marginal. Therefore, it is not surprising that the Inuit youth see little connection between the subjects taught in the high school and their practical life in the community. In other words, the situation represents a mismatch between curriculum and Inuit society. In mainstream society education conveys learners' goals for employment and success. However, the Inuit youth see their responsibilities to provide for their people by going out on the land as more relevant than sitting in a classroom. Since they are concerned for the future well-being of their communities these Inuit youth drop out of high school. Understood in this way, the problem lies not so much with the youth as with the difficulties posed for them to identify with the education system provided by the colonizer and which has historically been used to force Indigenous people to deny their own culture and assimilate into the mainstream. Perhaps the youth just want to be themselves, that is, to live on the land and continue life as Indigenous peoples. In any case, many of the old people still teach the youth the importance of being able to 'walk in two worlds.' This is in part the foundation of a vision established over four decades ago in which Canadian First Nations articulated principles of "Indian control of Indian education" [51] in order to integrate the kinds of education required for success in the contemporary world with appreciation for the kinds of traditional Indigenous values and practices that might encourage youth to spend time on the land as part of a socially inclusive curriculum.

\section{Idle No More: Struggles to Reposition Indigenous Representations and Rights}

One of the paradoxical features of the Idle No More movement has been its capacity to forge strong linkages as well as divisions. Some critics have dismissed Idle No More as a form of Indigenous radicalism that is hostile to the interests of other Canadians. Although more sharply focused than the earlier Occupy movements in New York and many other cities, Idle No More has also exposed some parallel internal divisions and divergent interests among its participants. Much of the media attention was focused on Chief Theresa Spence, who initiated the high profile hunger strike (or low liquid diet), and the other formal leaders of First Nations organizations across the country who variously led or protested meetings with senior Canadian government officials. This exposure heightened the profile given to several important priorities and grievances within Indigenous communities, but it also fostered images of internal bickering, indecisiveness and hypocrisy. Information based on an audit requested by the federal government was leaked to media outlets suggesting that Spence and other band counsellors were highly remunerated at a time in which large amounts of band spending intended to address education, housing and other critical infrastructure needs were not adequately documented [52].

These developments have provoked extensive rhetoric across both mainstream and social media sites, often denigrating both individuals like Spence and Indigenous people more generally for their apparent sense of entitlement, irresponsibility, and lack of accountability. Comments like the following draw upon and reinforce stereotypical opinions concerning Indigenous people based on racialized assumptions using meritocracy as the standard.

[My] house doesnt rot because i take care of it because i worked for it. Not the goverments job. That reserve has recieves over $\$ 425$ million from the federal goverment and the mine there blocking. Calling people names and saying they dont understsnd doesnt do much to help your position (sic [53]).

There is nothing wrong with Bill C-45. Everyone calls for Accountability by the government but generally we as citizens forget we need to be accountable for our own lives. The Government's job is not to find you a job, feed your kids and buy you a house. It's [sic] job is to ensure our economy is strong enough for you to do that on your own [54].

It's all great that people want more, but generally people don't hold themselves accountable...Free giveaways will not help the country, we all have to do our part [55].

Stereotypes rooted in colonial power relations remain embedded with these comments, akin to the pervasive inequalities observed in the previous section regarding the criminal justice system. The denigration of Indigenous people as lazy, apathetic and indifferent both ignores and reinforces the impact of longstanding experiences of systemic discrimination and colonization. The racialized interpretations continue colonial practices ("blaming the victim", "divide and conquer") that criticize Indigenous people for their impoverishment while embracing the misguided premise that Canada is a meritocracy in which social and economic status are presumed to have little to do with race, class and gender in the reproduction of social inequality. Indigenous people are portrayed in these discourses as dependent on government largesse and are otherwise deserving of nothing else than the direction to take responsibility for their own "problems".

At the same time, Idle No More has fostered alternative discourses and social alignments. The highly charged racialized discourses have created opportunities to raise consciousness among Indigenous people and other Canadians regarding the impact of racism as well as the conditions which have fostered it. Idle No More is a movement that has been spurred and embraced most strongly by relatively young and articulate segments of the Indigenous population who are adept at integrating educational success and the 
powers of social media with experiences and lessons derived from previous generations. As a consequence, the core activities such as maintenance of a website and Facebook page and organization of public events are predominantly urban-based while the movement has been highly successful in mobilizing support from a wide spectrum of Indigenous and non-Indigenous communities. The spirit of the movement is perhaps best exemplified in the initiative undertaken by a group of young people who walked 1600 kilometres from their Cree community in northern Quebec to Ottawa in winter conditions to draw awareness to social conditions in Indigenous communities and reconnect with their land and heritage. The group, which began with seven walkers, had increased to as many as four hundred by the time it was greeted by thousands of cheering supporters on its arrival in Ottawa in late March. Some of the group members indicated that the walk had helped them address serious personal issues such as depression and suicidal thoughts [56]. The march also proved inspiration for many others across the nation, as reflected in blog commentaries on media reports such as the following:

I am impressed by these young people. What a journey! I love how they found a way to demonstrate their beliefs-it connects them to their culture (the route and way of traveling) and the land to their protest. It will have long term positive affects [sic] on their lives. I wish them all well and safe travels [57].

Congrats! All young should witness this courage, endurance and sense of community. I hope this experience showed them what great opportunities can lie ahead in this great land [58].

While not all comments were as supportive or positive, the initial responses suggest that educational moments have created opportunities to embrace a pathway towards the kinds of meaningful inclusion Indigenous people are seeking in the Canadian context.

\section{Conclusion}

Although the Idle No More movement seems to have disappeared from the media, it is in fact very much alive and vital in and beyond Indigenous communities. Idle No More has not disappeared but has demonstrated its deep roots as part of an established system of cultural teachings and values that advocate respect for the environment that has been continuously reproduced to the present time. Idle No more speaks of modern Indigenous interpretations of development that are rooted in the ideology of future wellbeing of succeeding generations. Indigenous peoples across Canada and their supporters in many nations openly protested against Bill-C-45 because of the importance of sustaining the environment within Indigenous cultures and knowledge systems, revealing Idle No More as a manifestation of Indigenous values and its fundamental teaching to take care of the land and water. The focal points for the movement, however, reach well beyond a single piece of legislation and the manner in which it was implemented.

We have discussed Idle No More with reference to diverse frameworks and bodies of literature, including the analysis of social inclusion, Bourdieu's concepts of habitus, field and forms of capital, and Indigenous conceptions of knowledge and justice in order to understand the potential implications the movement has for Indigenous people and for Canadian society. Inclusion has different meanings and implications for diverse populations, representing differential positioning within relations of power as well as in struggles to define and gain access to the kinds of social and cultural resources that influence the kinds of social, economic and political positions occupied by members of these populations. For Canada's Indigenous people, these issues have often been posed as making a choice or being forced to shed Indigenous identity and cultural roots or risk being marginalized, despite a legal framework that recognizes Indigenous rights and nationhood. The falseness of this dichotomy and what it represents is belied by a historical experience of colonization and more recent barriers to meaningful social and economic participation, combined with a political environment in which Indigenous rights are ignored or remain contested.

The phenomena described in this paper point to a double failure, on the part of governments and other official agencies, but they also suggest the emergence of dual promise. They reveal, at the same time, the importance of understanding and approaching social inclusion as a complex, multidimensional phenomenon that is defined and approached in diverse and sometimes conflicting ways by different populations. Some of Canada's Indigenous people are gaining entry into and prominence within the social, economic and political structures of Canadian society, but substantial barriers continue to limit the extent to which full inclusion has been possible for the majority of Indigenous people. Government policies and the practices related to them have persistently fallen short both in fostering conditions by which Indigenous people have been able to gain meaningful engagement in many aspects of Canadian life and in providing a solid foundation on which Indigenous aspirations for self-determination can be fulfilled. They have also rekindled counter-discourses grounded in misunderstanding of these relationships, often reinforcing hostility and overt racism. The promise, by contrast, lies with the awakening in the communities, potentially drawing together youth and elders, reaching across an extensive breadth of the Indigenous experience in Canada, ranging from upwardly mobile urban professionals, seasonal resource industry workers and those who have given up hope of meaningful employment, communities whose lives depend on relations with the land, victims 
of abuse and criminalization, and many others. By drawing attention to these issues, even in the face of negative criticism, they have helped foster dialogue and understanding that are essential for moving forward in validating Indigenous knowledge and identities and clarifying and achieving a nation to nation arrangement. While the directions and outcomes associated with these dialogues remain highly uncertain, they highlight what must occur in order for any effective, progressive change with respect to Indigenous people's status in relation to Canadian society. There are dangers that Idle No More may fragment regardless of how governments and other agencies respond to it, akin to the failure experienced by numerous previous efforts to bring together and respond adequately to the voices of those who represent the full diversity of Indigenous positions and perspectives. At the same time, there are signs that it can be as resilient as the Indigenous knowledge and traditions that were not extinguished by colonialism, in part because it is deeply informed by and respectful of those traditions, while at the same time mobilizing and motivating younger generations. It suggests a way forward, to the extent that the authority grounded in Indigenous knowledge can be integrated with the kinds of legitimacy accorded a cohort of Indigenous people moving into influential positions within Canadian institutional life while seeking validation of their rights and heritage as Indigenous people. It also requires that we pay careful attention to the changing positions of and coalitions engaged in by Indigenous people and their allies in terms of their significance for Canadian and other societies.

As a movement and culture challenging the destruction of the environment, Idle No More builds upon people's sense of humanity that emerges from a conscious awareness of natural laws and the realization that Indigenous peoples have suffered unjustly from social exclusion and colonization. It has practical and political significance for the choices and directions taken by the Canadian state and its people, with the potential to inform specific policy deliberations as well as the understanding of relations of ruling and resistance that shape these options. As a grassroots social

\section{References and Notes}

1. Coulthard G. Idle No More in Historical Context. Decolonization: Indigineity, Colonization and Resistance. 24 December 2012. Available from: http://decol onization.wordpress.com/2012/12/24/idlenomore-in-hi storical-context/\#more-50 (accessed on 13 February 2013).

2. Gordon J. Manifesto. Idle No More. 13 January 2013. Available from: http://idlenomore.ca/about-us (accessed on 28 May 2013).

3. Parliament of Canada. Statutes of Canada 2012. Chapter 31. A second act to implement certain movement, its genesis and direction can inform and be informed in a reflexive manner by the variously failed or successful trajectories of other major social movements in North America and other parts of the world (see, e.g., [59]). It obliges us to acknowledge and act upon our responsibilities, as people who represent one or the other party to living treaties, while focusing our attention at the same time to our wider responsibilities as human beings. For those interested in questions of social inclusion, it points to complex questions that researchers and policy-makers in many contexts must pay attention to regarding who defines inclusion and what inclusion signifies for those in different social and economic positions.

The movement reminds us that any future research agenda concerning Indigenous social inclusion and exclusion has a responsibility to uphold Indigenous perspectives. Traditional knowledge and cultural resources, along with longstanding responsibilities to the land, resources and other people, lie at the core of those perspectives. We have observed Idle No More's capacity for unity, despite the efforts of participants and observers both within and outside the movement to steer it in various alternate directions. The movement has shown that Indigenous people are conscious of their inherent laws and demonstrated that a profound responsibility is to uphold those laws for the benefit of future generations. It has mobilized young generations in unique ways, stirring new interest in the teachings of the elders and their relevance for today. Idle No More has demonstrated the need to promote open communication between governments, Indigenous people and mainstream Canadian citizens. For academic researchers as well as political observers, ongoing attention is needed to explore both the roots and possible futures of the movement and the kinds of influence, if any, it will generate over time. It reminds us that the achievement of inclusion can only be understood in terms of the capacity to incorporate and offer validation for a variety of perspectives, experiences and socioeconomic outcomes all oriented to the objective to foster a viable and sustainable way of living.

provisions of the budget tabled on March 29, 2012 and other measures. Ottawa, Canada: Parliament of Canada; 14 December 2012.

4. United Nations. United Nations Declaration on the Rights of Indigenous Peoples. New York, NY, USA: United Nations; 2008.

5. Houle SM. INM: Seeing Only Bill C-45 Helps Harper's Plans Be Realized. Idle No More website. 5 May 2013. Available from: http://idlenomore.ca/articl es/resources/selected-readings/item/222-inm-seeing-o nly-bill-c-45-helps-harper\%E2\%80\%99s-plans-be-real ized (accessed on 27 May 2013).

6. Cannon M, Sunseri L, editors. Racism, Colonial- 
ism, and Indigeneity in Canada: A Reader. Don Mills, ON, Canada: Oxford University Press; 2011.

7. Garner R, Carrière G, Sanmartin C. Longitudinal Health and Administrative Data Research Team. The Health of First Nations Living Off-Reserve, Inuit, and Métis Adults in Canada: The Impact of Socioeconomic Status on Inequalities in Health. Ottawa, Canada: Minister of Industry, Statistics Canada; 2010.

8. Wotherspoon T. Aboriginal People, Public Policy, and Social Differentiation in Canada. In: Juteau D, editor. Social Differentiation: Patterns and Processes. Toronto, Canada: University of Toronto Press; 2003. pp. 155-204.

9. Usalcas J. Aboriginal People and the Labour Market: Estimates from the Labour Force Survey, 2008-2010. Ottawa, Canada: Statistics Canada Labour Statistics Division; 2011.

10. Lutz JS. Makuk: A New History of AboriginalWhite Relations. Vancouver, Canada: UBC Press; 2009.

11. Adams H. Prison of Grass: Canada from the Native Point of View. Toronto, Canada: New Press; 1975.

12. Alfred T. Peace, Power, Righteousness: An Indigenous Manifesto, 2nd ed. Don Mills, Canada: Oxford University Press; 2009.

13. Denis JS. Transforming Meanings and Group Positions: Tactics and Framing in Anishinaabe-White Relations in Northwestern Ontario, Canada. Ethnic and Racial Studies. 2012;35(3):453-470.

14. Bird J, Land L, Macadam M, editors. Nation to Nation: Aboriginal Sovereignty and the Future of Canada. Toronto, Canada: Irwin Publishing; 2002.

15. Helin C. Dances with Dependency: Out of Poverty through Self-Reliance. Woodland Hills, CA, USA: Ravencrest; 2008.

16. Yashar DJ. Contesting Citizenship in Latin America: The Rise of Indigenous Movements and the Postliberal Challenge. Cambridge, UK: Cambridge University Press; 2005.

17. Hedetoft UR. Social Inclusion: Inaugural Editorial. Social Inclusion. 2013;1(1):1-2.

18. Giddens A. The Third Way: The Renewal of Social Democracy. Malden, MA, USA: Polity Press; 1998.

19. Banting KG. Dis-Embedding Liberalism? The New Social Policy Paradigm in Canada. In: Green DA, Kesselman, JR, editors. Dimensions of Inequality in Canada. Vancouver, Canada: UBC Press; 2006. pp. 417-452.

20. Esping-Andersen G. A Welfare State for the 21st Century. In: Giddens A, editor. The Global Third Way Debate. Cambridge, UK: Polity Press; 2001. pp. 134-156.

21. Lister R. Strategies for Social Inclusion: Promoting Social Cohesion or Social Justice? In: Askonas P, Stewart A, editors. Social Inclusion: Possibilities and Tensions. Basingstoke, UK: Macmillan Press; 2000. pp. 37-54.

22. Government of Canada. Responsible Resource Development-Overview. Canada's Economic Action
Plan. 2013. Available from: http://actionplan.gc.ca/en/ page/r2d-dr2/overview (accessed on 29 March 2013).

23. Bourdieu P. The New Capital. Appendix: Social Space and Field of Power. In: Bourdieu P. Practical Reason: On the Theory of Action. Stanford, CA, USA: Stanford University Press; 1998. pp. 31-34.

24. Bourdieu P, Passeron J-C. Reproduction in Education, Society and Culture. Beverly Hills, CA, USA: Sage; 1979.

25. Levitas R. The Inclusive Society? Social Exclusion and New Labour, 2nd ed. Basingstoke, UK: Palgrave Macmillan; 2005.

26. Daly $M$, Silver $H$. Social Exclusion and Social Capital: A Comparison and Critique. Theory and Society. 2008;37(6):537-566.

27. Department of Aboriginal Affairs and Northern Development Canada. Education. Available from: http://www.aadnc-aandc.gc.ca/eng/1100100033601/1 100100033605 (accessed on 24 May 2013).

28. Lamont M, Lareau A. Cultural Capital: Allusions, Gaps and Glissandos in Recent Theoretical Developments. Sociological Theory. 1988;6(5):153-168.

29. Lareau A, Horvat EM. Moments of Social Inclusion and Exclusion: Race, Class, and Cultural Capital in Family-School Relationships. Sociology of Education. 1999;72(1):37-53.

30. King T. The Inconvenient Indian: A Curious Account of Native People in America. Toronto, Canada: Doubleday Canada; 2012.

31. Palmater PD. Beyond Blood: Rethinking Indigenous Identity. Saskatoon, SK, Canada: Purich Publishing; 2011.

32. Hawboldt A. Don't Let Me Be Misunderstood: Idle No More Founder Sets the Record Straight. Verb 2013;228(February):4-5.

33. Yazzie R, Zion JW. Navajo Restorative Justice: The Law of Equity and Harmony. In: Galway B, Hudson J, editors. Restorative Justice: International Perspectives. Monsey, NY, USA: Criminal Justice Press; 1996. pp. 157-174.

34. Hansen JG. An Exploration of Swampy Cree Restorative Justice. PhD Thesis, Department of Curriculum Studies in Education, University of Regina, SK, Canada; 2010.

35. Henderson JY. Postcolonial Ledger Drawing: Legal Reform. In: Battiste $M$, editor. Reclaiming Indigenous Voice and Vision. Vancouver, BC, Canada: UBC Press; 2000. pp. 161-171.

36. Comack E. Racialized Policing: Aboriginal People's Encounters with the Police. Halifax, Canada: Fernwood Publishing; 2012.

37. Yazzie R. Indigenous Peoples and Postcolonial Colonialism. In: Battiste $M$, editor. Reclaiming Indigenous Voice and Vision. Vancouver, BC, Canada: UBC Press; 2000. pp. 39-49.

38. Truth and Reconciliation Commission of Canada. Interim Report. Winnipeg, MB, Canada: Truth and Reconciliation Commission of Canada; 2012.

39. Truth and Reconciliation Commission of Canada. 
They Came for the Children: Canada, Aboriginal Peoples, and Residential Schools. Winnipeg, MB, Canada: Truth and Reconciliation Commission of Canada; 2012.

40. Sutherland J. Colonialism, Crime, and Dispute Resolution: A Critical Analysis of Canada's Aboriginal Justice Strategy. 2002. Available from: http://www.me diate.com/articles/sutherlandJ.cfm (accessed on 5 May 2008).

41. Nobles M. The Politics of Official Apologies. Cambridge, UK: Cambridge University Press; 2008.

42. Smith LT. Decolonizing Methodologies: Research and Indigenous Peoples. London, UK: Zed Books; 1999.

43. Atkinson $A B$, Marlier E. Analysing and Measuring Social Inclusion in a Global Context. New York, NY, USA: United Nations, Department of Economic and Social Affairs; 2010.

44. Canadian Criminal Justice Association. Aboriginal Peoples and the Criminal Justice System. 2000. Available from: www.ccja-acjp.ca/en/aborit.html (accessed on 13 January 2003).

45. Brosnahan M. Record-high Prison Numbers Sparking Violence. CBC News. 27 August 2012. Available from: http://www.cbc.ca/news/politics/story/ 2012/08/27/prison-numbers-crowding.html (accessed on 18 September 2012).

46. Office of the Correctional Investigator, Government of Canada. Spirit Matters: Aboriginal People and the Corrections and Conditional Release Act. Final Report. Ottawa, Canada: Office of the Correctional Investigator of Canada; 2012.

47. Braithwaite J. A Future Where Punishment Is Marginalized: Realistic or Utopian? UCLA Law Review. 1999;46(6):1727-1750.

48. Commission on First Nations and Métis People and Justice Reform. Legacy of Hope: An Agenda for Change. Final Report Volume 1. 2004. Available from: www.justicereformcomm.sk.ca (accessed on 14 March 2013).

49. Foucault M. Discipline and Punish: The Birth of the Prison. New York, USA: Vintage Books; 1977.

50. Canadian Council on Social Development. Social Inclusion and Communities at Risk: Canada's Aboriginal Peoples. 2003 Social Inclusion Conference
Proceedings. Available from: http://www.ccsd.ca/ev ents/inclusion/proceedings/aboriginal.htm (accessed on 13 February 2013).

51. National Indian Brotherhood. Indian Control of Indian Education. Ottawa, Canada: National Indian Brotherhood [Assembly of First Nations]; 1972.

52. By contrast, relatively little media was focused on observations within the audit report that there had been some improvement in financial accounting practices during Spence's term as Chief. See: Schwartz D. Inside Attawapiskat's financial troubles. CBC News. 9 January 2013. Available from: http://www.cbc.ca/ news/canada/story/2013/01/09/f-attawapiskat-finance s-faq.html (accessed on 30 May 2013).

53. "LM". Posted on Entitled No More Facebook page. Available from: https://www.facebook.com/whe resthemoneygoing (accessed on 12 February 2013).

54. "Sean". Posted on CBC Live Blog. Available from: http://www.cbc.ca/news/politics/story/2013/01/ 30/politics (accessed on 30 January 2013).

55. "Guest". Posted on CBC Live Blog. Available from: http://www.cbc.ca/news/politics/story/2013/01/ 30/politics (accessed on 30 January 2013).

56. Canadian Broadcasting Corporation (CBC). Cree walkers speak at Parliament Hill after Idle No More trek: 'Journey of the People' ends with crowds cheering aboriginal youth. Available from: http://www. cbc.ca/news/canada/ottawa/story/2013/03/25/ottawa -walk-nishiyuu-journey-ends-ottawa-parliament-victori a.html (accessed on 25 March 2013).

57. "Philip". Posted on CBC Live Blog. Available from: http://www.cbc.ca/news/canada/ottawa/story/ 2013/03/25/ottawa-walk-nishiyuu-journey-ends-ottaw a-parliament-victoria.html (accessed on 25 March 2013).

58. "Lraymond". Posted on CBC Live Blog. Available from: http://www.cbc.ca/news/canada/ottawa/st ory/2013/03/25/ottawa-walk-nishiyuu-journey-e nds-ottawa-parliament-victoria.html (accessed on 25 March 2013).

59. Wood LJ. Direct Action, Deliberation, and Diffusion: Collective Action after the WTO Protests in Seattle. New York, NY, USA: Cambridge University Press; 2012. 